\title{
THE SURGERY OF BRAIN DAMAGE ${ }^{\dagger}$
}

\author{
J. C. DE VILLIERS* M.D., F.R.C.S. (Eng. \& Edin.)
}

'n Oorsig van chirurge in breinskade word gegee. Voorkomende en palliatiewe chirurgie word kortliks bespreek. Chirurgie in spastisiteit sluit in neurektomie, risotome en longitudinale mielotomie en die voor- en nadele word bespreek. Serebellêre dentatotomie en ander chirurgie vir abnormale bewegings dateer van 1890 en word nog vandag bebruik. Chirurgie in die basale ganglia area word in uitsonderlike gevalle aangedui. Ten laaste word chirurgie vir epilepsie en verhoogde intrakraniale druk bespreek.

In the central nervous system, there is no regeneration of neurones which have been irreversibly damaged so that their function has to be taken over, if at all possible, by other neurones. Such functional take-over may be impossible where highly specialised cells, such as those concerned with vision, have been lost. What little evidence there is of axonal sprouting after injury, does not as yet apply to man and the effects may be as much deleterious as beneficial.

It therefore stands to reason that prevention must be our foremost concern at all times, as many forms of brain damage are almost entirely preventable, for example birth injury and head injuries resulting from road crashes.

\section{PREVENTIVE SURGERY}

All space demanding lesions such as intracranial haematomas, abscesses, cysts and tumours, lead to brain damage by virtue of pressure and should therefore be treated promptly. Prolonged raised intracranial pressure may cause secondary shifts of the brain producing compression of the brain stem or vascular occlusion with resultant infarction which can be prevented by early removal of the causative lesion. This is the underlying basis of the neurosurgeon's sense of urgency in dealing with these problems. He is only too painfully aware of the disastrous effects of delay.

Transient neurological episodes suggestive of carotid or vertebral flow imnairment should lead to full investigations to exclude the presence of a treatable lesion, such as a carotid artery stenosis or subclavian steal syndrome. Once a patient has transient ischaemic attacks, there is a risk of over $50 \%$ of a completed stroke developing within 18 months. Surgery for removal of the source of emboli and relief of a mechanical stenosis with restoration of adequate cerebral bloodflow, is reasonably simple and safe.

Similarly, the treatment of intracranial aneurysms and arteriovenous malfnrmatinns is rot airnod nit cure of the damage already done, but to prevent rebleeding and further damage which may be fatal.

Every person involved in the management of unconscious patients, should at all times be concerned with the patient's respiratory function so that adequate oxygenation of the blood reaching the brain is ensured. Cerebral hypoxia is probably the most frequent yet, most easily preventable cause of brain damage.

* Helen and Morris Marerbcrger Professor of Neurosurgery, University of Cape Town and Groote Schuur Hospital.

$\dagger$ Adapted from a paper delivered at a postgraduate course on "Early Treatment of the Head Injured Patient" held at the University of Cape Town, July 1976.
Management of the secondary effects of brain damage may be primarily medical, as in the treatment of spasti. city and epilepsy, or, it may be surgical in which case it may fall within the sphere of the general surgeon, the orthopaedic surgeon and the neurosurgeon. This communication is concerned particularly with the neuro. surgical aspects of treatment of brain damage.

\section{PALLIATIVE SURGERY}

At the outset it must be clearly stated that surgery cannot be the be-all and end-all of treatment of any patient with brain damage. Surgery is merely a part of the total management and must be integrated into the individual treatment programme for the patient Most of these operations are destructive procedure to a greater or lesser extent and to advise surgery this nature in a patient who already has gross los of function, is a step not to be taken lightly.

Remarkable results following surgery are often due as much to the personal attributes of the patient, his drive and commitment, as to the surgical procedure Children with brain damage who have successful operations, usually have parents with the ability to guide their disabled child through his therapy to become a balanced personality despite physical handicaps and their psychological concomitants.

\section{SURGERY OF SPASTICITY}

Spasticity is a common result of brain and spinal cord damage in adults and children. It is a release effect from the normal tonic inhibitory influence on cells which subserve somatic motor functions. If the basic pathology cannot be affected by treatment, therapy is directed at the final common pathway subserving muscle tone. It is well known how spasticity can hamper a patient's progress and how relief of spasticity by physiotherapeutic, medical or surgical means, can at times restore a patient to activities which before would have been thought impossible. Non-surgical means of alleviating spasticity, should be given an adequate trial before resorting to surgery. There is no point in adopting a die-hard attitude to some method of treatment and stretching the patient on the rack that particular method, waiting for a miracle. If $t$. patient is progressively getting worse, denying him the benefit of adequate surgery is as foolish as surgical overenthusiasm.

The aims in treatment of spasticity are:-

1. To relieve spasticity, and

2. To retain, if $n n t$ improve, motor, sensory or sphincter function.

The final neural pathway for spasticity traverses the afferent fibres, the interneurones and efferent neurones at any particular spinal segment. Chemical or surgical treatment is directed at interruption of afferent, interneuronal or efferent pathways. Treatment by tenotomy or tendon lengthening deals with the mechanical effects of spasticity.

\section{NEURECTOMY}

This may be performed either by chemical or surgical means and usually interrupts efferent and afferent pathways to a muscle.

\section{Chemical Neurectomy}

Local injection of phenol or alcohol to interrupt 
function in a nerve has a well-defined place in treating function ty. The muscle nerve points in question are spalized with stimulating electrodes and then injected. localects are, however, transient (Cain et al, 1966); (Lacombe et al, 1966). Phenol injection into spastic muscles has been used particularly in mobilising the pastic arm and hand in hemiplegic patients. The obsurator nerves may be painted at open operation with phenol to relieve adductor spasm.

\section{Surgical Neurectomy}

The most frequent operation of this type is oburator neurectomy for adductor spasm in the legs.

There are a few basic criticisms of neurectomy, the first being that a peripheral nerve is sectioned. If it is mixed nerve, there is sensory loss with its attendant risks. Irrevocable loss of muscle power occurs and muscle wasting and later contracture of the wasted muscle may follow. Neurectomy is not rejected entirely, but plays a very clearly defined, if limited, part in the management of spasticity.

\section{RHIZOTOMY}

\section{Surgical Posterior Rhizotomy}

In 1898, Sherrington demonstrated that decerebrate rigidity in experimental animals could be reduced by posterior nerve-root section. This effect is due to interruption of afferent input from muscle spindles as well as other receptors.

Foerster in 1908 applied this concept to man by performing posterior root section for spasticity so as to reduce the sensory input which propagates spasticity. This involved section of L. 2, 3, 4, 5 and S.1 posterior roots. The idea was to leave some posterior root sensory areas intact as it rapidly became apparent that the sensory loss was a major deficit to some of these patients who were immobile on account of their paraplegia. The beneficial effects, however, were of short duration so that this operation fell into disrepute fairly quickly.

Anterior Rhizotomy was introduced by Munro in 1945. It does provide complete relief of flexor spasms but at the price of flaccid paralysis and can therefore only be done below the level of complete cord lesions.

in both these kinds of rhizotomy, permanent loss of neural function follows in a person already neurologically disabled, and there is no hope of any resovery ever. Patient selection has therefore to be exfemely careful.

\section{Selective Anterior Rhizotomy (Munro, 1952)}

Every second or third fascicle of the particular nerveroot concerned is divided so as to reduce motor outflow two- or threefold. If too many fascicles are divided, flaccid paralysis ensues. It was a valuable method but lacked proper physiological control.

\section{Functional Posterior Rhizotomy}

To overcome the difficulties of sensory loss and paralysis following root section, various types of selestive posterior root section have been developed [Gros et al (1971), Fraioli \& Guidetti (1977)]. Fascicles of roots are sectioned according to the effects produced by electrical stimulation or every fascicle is partially sectioned, or, only 2 or 3 fascicles in a posterior root are left intact. This is usually done in the lumbar region because not all fascicles are divided or divided completely. There is no extensive sensory loss and no extensive motor deficit. This method works on the basis of reduction in total input without loss of essential sensation, particularly proprioception.
What is somewhat surprising at first, is that there is relief of spasticity at levels higher than the area sectioned, particularly in children with cerebral palsy. Experimental justification for this has been provided by Kirk and Denny-Brown (1970). There is in these children inadequate suppression of input and by reducing the afferents at a few segments, lessens the total input into the entire nervous system which can then function better even at higher levels.

\section{Chemical Rhizotomy}

Maher (1957) treated a series of patients with intrathecal phenol for various indications and in this group included a patient with severe flexor spasms. This method was rapidly accepted and developed particularly by Nathan $(1959,1965)$. It is a method of treatment with considerable risks attached to it if not correctly carried out, but, if the necessary precautions are taken and the injection of the correct strength of phenol solution given under perfect radiological and clinical control, it becomes virtually risk-free. It can allow function to be recovered by removal of disabling spasticity and it can even be given to ambulant patients without producing added neurological deficit. It works on the basis of non-selective destruction of nerve fibres in the posterior nerve roots which consequently reduces the inflow of impulses into the affected segments.

The disadvantages of the method are, in the first place, the risks attached to it and the danger of impairing bowel and bladder function. Several roots are affected and undesirable muscle weakness may develop. In some patients the initial satisfactory effects may not be lasting;

To limit the phenol effect to the desired nerve roots, Harris and Simpson (1964) suggested laminectomy for these patients and painting of the nerve roots, indicated by electrical stimulation, with glycerin and phenol. Even this procedure may be only trarsiently effective and adds the burden of a laminectomy to patients rather severely disabled already.

\section{LONGITUDINAL MYELOTOMY}

\section{Bischoff Type 1 (1951)}

Lateral longitudinal myelotomy is directed at cutting longitudinally the association fibres of Kölliker running between the anterior and posterior horns and in this way interrupting some of the interneurones concerned in maintaining spasticity. Lateral longitudinal incisions are made in the spinal cord, along the line of the dentate ligaments from L.1 to S.I. If the bladder is spastic, one side is cut down to S.5. Bischoff noted that this operation relieved spasticity but tended to interfere with the corticospinal tract and decussating sensory fibres and therefore modified the operation.

\section{Bischoff Type 2 (1967)}

This is a median posterior longitudinal myelotomy. An incision is made in the midline posteriorly to the level of the central canal and lateral extensions are then made at right angles to the initial incision interrupting the connections between anterior and posterior horns, but without any damage to the corticospinal tracts. A considerable number of these operations have been done and the results have been very promising. We have done three with rather satisfactory resılts and no loss of neurological function. All three patients were restored to activities which they had not had before.

\section{CEREBELLAR DENTATOTOMY}

The effect of cerebellar lesions on tone have been known for a long time. Clinical application of these 
facts to patients with abnormalities of posture and tone, stems from the work of Nashold and Slaughter (1969). The operation is stereotactically performed and is based on the theoretical assumption that increased output along the dentato-rubrothalamic pathways can be eliminated by partial dentate destruction. Improvement in spasticity is usually more marked in proximal than distal muscle groups. Tremor may occur as a complication of the operation, particularly if the lesion is placed too far medially. This operation has its greatest application in the treatment of cerebral palsy (De Klerk, 1973).

The number of procedures available for the treatment of spasticity should indicate that not one procedure is universally applicable or successful. It has to be emphasized that spasticity is a clinical concept which results from different patho-physiological mechanisms varying from the site and nature of the lesion(s) in the nervous system.

\section{THE SURGERY OF ABNORMAL MOVEMENTS}

Choreo-athetosis is common in children as part of the cerebral palsy syndrome. They do not only have disturbing abnormal movements but also abnormalities of posture. The evolution of the surgical treatment of these children is a long and fascinating one, beginning in 1890 when Sir Victor Horsley partially excised the prefrontal motor area in a child with severe hemiathetosis with temporary relief. He suggested that the entire motor area should have to be excised for permanent effect on movement. In 1907 he reported another child with hemiathetosis who had permanent loss of spasmodic movements with partial recovery of movement of the left arm, after the initial postoperative paralysis but had permanent sensory loss on the left.

This operation was more or less forgotten except for sporadic reports till 1932, when Bucy and Buchanan revived this work by subpial excision of the motor and premotor strips with some success and noted that the dystonic movements were less favourably affected than the choreic (Bucy, 1951).

Any cortical operation left the patient not only with some weakness which could perhaps be regarded as a reasonable exchange but also with a very real risk of added post-traumatic epilepsy. Occasionally, however, patients had better motor function after operation than before.

A more limited attack on the so-called pyramidal tract was directed at the corticospinal motor tracts in the cerebral peduncles (Walker, 1949). This is a difficult operation as the anatomy does not conform to the textbook description; even electrostimulation does not resolve the problem completely. The results are variable and not always lasting, but it has retained a certain popularity in the hands of some surgeons (Maspes \& Pagni, 1964).

\section{SPINAL TRACTOTOMY}

Surgery directed at the upper cervical spine such as anterior column section, has met with little acceptance because of the motor and sensory deficits incurred when adequate relief of choreo-athetosis was obtained (Putnam, 1942).

\section{BASAL GANGLION SURGERY}

Direct surgical attack on the basal ganglia in the treatment of dyskinesias, was pioneered by Meyers (1942). With the development of stereotactic surgery, this method became the accepted way of dealing with movement disorders. The advantages are that a small lesion may be accurately placed in a pre. determined target such as the globus pallidus or ventro-lateral nucleus of the thalamus without damag. ing the motor or sensory tracts. By 1953, Narabayashi could report that about $50 \%$ of the first group of choreo-athetotic patients treated by chemopallidectomy, were improved and in 1962, he reported a $78 \%$ im. provement in children with cerebral palsy and move. ment disorders.

Only children without evidence of spasticity and of near normal intellect, are suitable candidates $f_{0 r}$ thalamotomy, which may aggravate spasticity. Most authors believe that dystonic and choreiform move. ments are helped more than athetosis by thalamotomy. In our experience with two patients, dystonia has re. sponded extremely well to venrolateral stereotactic thalamotomy.

\section{SURGERY FOR SEIZURES}

An area of cerebral tissue may be destroyed by wide variety of pathological processes such as vasculf occlusion, haemorrhage, inflammatory lesions, mechan cal trauma or compression by any expanding intra cranial mass. When this destroyed area heals, functional normality does not necessarily return and it may become an epileptogenic focus. It should be noted that the epileptic discharge does not originate in the lesion but in the border zone between it and normal brain. Usually, such a focus lies in the cortex.

\section{Indications for Surgery}

A focal lesion producing partial or generalized epilepsy such as a brain tumour, A-V malformation, cyst or abscess, which can be removed safely and with minimal additional surgical trauma. Usually, these patients are operated upon because of cerebral compression rather than epilepsy, which is regarded as incidental and symptomatic.

Epilepsy which is uncontrollable medically, and which originates from a localized focus that can be removed without producing new neurological deficit. Removal is best done by hemispherectomy or cortical scar excision.

\section{Hemispherectomy}

A small group of children with infantile hemiplegia developed intractable epilepsy and later severe be havioural disturbances. The cause of the hemiples may vary. The epilepsy may be partial or generalize. but, usually the latter. Behaviour disturbances are the most notable feature of this disorder: temper tantrums, violence, cruelty towards weaker individuals, and lack of discipline are the outstanding features. There are gross EEG abnormalities and plain $X$-rays show asymmetry of the skull while air studies reveal marked unilateral ventricular enlargement.

For this kind of problem, Krynauw (1950) performed hemispherectomy, removing the almost completely destroyed hemisphere. A large number of cases have been reported (McKissock 1953, Wilson 1970). Despite occasional late deaths due to haemorrhagic complications, 2 out of 3 of the survivors are seizure-free and a further $14 \%$ much improved. It is probably the most radical and also the most successful operation for epilepsy. It does not add to the patient's neurological deficit, which may indeed be lessened.

The success with this pioneering operation, led to Penfield's work on temporal lobe epilepsy as a result of which patients with this type of epilepsy, are the ones most likely to benefit from surgery in the form of temporal lobectomy, provided that the correct indications are adhered to. 


\section{Excision of cortical scars}

Surgery for the cure of this type of epilepsy must include the mapping and removal of the entire epiincluc area without producing any new neurological deficit.

There is a very low mortality in this type of surgery The success rate (total abolition or marked reducand in seizures) is about $50 \%-70 \%$, but the failure tion in virtually constant. For success, strict indications rate must have failed. Careful clinical and laboratory inmestigations must indicate that there is a focal cortical vestigat present and the area of cortex involved must be dispensable without adding to the patient's neurological deficit. (Rasmussen, 1969). There are other forms of surgery for epilepsy but their results are less predictable and their application has not become widespread.

\section{Surgery of abnormal behaviour}

Some epileptics develop severe behaviour disorders much as aggressiveness, extreme restlessness, destructiveness and unprovoked violent behaviour. When all medication fails, and the patient can only be institutionalised, certain forms of surgery may give relief; the "sedative surgery" of Sano. Stereotactic amygdalotomy, cingulotomy and postero-medial hypothalamotomy have all been reported as being beneficial but this is surgery which should not be lightly undertaken on account of the moral and ethical considerations involved.

\section{THE SURGERY OF RAISED INTRACRANIAL PRESSURE}

Brain damage may follow on elevated intracranial pressure as indicated earlier on. There are two conditions which deserve special mention. The commonest is the development of hydrocephalus after any form of cerebral injury and the other is porencephaly.

\section{Hydrocephalus}

Any lesion which leads to obstruction of the outflow of a lateral ventricle, third ventricle, aqueduct or fourth ventricle, or even which leads to obstruction of the temporal horn of one lateral ventricle may cause a varying degree of hydrocephalus proximal to the level of obstruction. Hydrocephalus produces secondary damage due to stretching of the paraventricular fibres and pressure. The symptoms of raised intracranial pressure such as headache, vomiting and papilloedema, are to be watched for. Perhaps more important than these, although a little more subtle, are sumptoms such as failure of concentration, intellectual fall-off and loss of recent memory. The latter ones may present themselves earliest of all to the therapist. The medical attendant should take heed of these complaints to prevent irreparable brain damage by early surgery. Investigations often show a so-called occult hydrocephalus where there are no symptoms of raised intracranial pressure but only those of intellectual impairment, unsteadiness of gait and incontinence of urine. There are many methods available for treating hydrocephalus pressure surgically. and these can be very effective in restoring a patient to normal life.

\section{Porencephalic Cysts}

These cerebral cavities of varied aetiology occur particularly in children. They occur within the cerebral substance and communicate with the CSF pathways.
Such communications may become smaller or blocked off and as fluid is being pumped into them without any outflow, they become secondarily space demanding. They need early management to prevent further damage to the brain which has already suffered conconsiderable injury.

\section{CONCLUSION}

A wide range of clinical conditions and a large number of surgical procedures have been mentioned. They may seem confusing, but it does indicate the inadequate state of our knowledge and therapy of the brain damaged individual. Careful patient selection for surgery is essential if success is to be expected. For this personal contact with the patient and a thorough understanding of his problems must be established by the therapeutic team of which the surgeon must function as a part.

\section{References}

Bischoff, W. (1951), Zbl. Neurochir. 11:79.

Bischoff, W. (1967), Zbl. Neurochir. 28:123.

Bucy, P. (1951), J. Neurol. Neurosurg. \& Psychiat. 14:108.

Bucy, P. and Buchanan, D. H. (1932), Brain 55:479.

Cain, H. D., Glass, A., Spiegler, J., Liebgold, H. and Mead, S. (1966-67), Paraplegia 4:166.

De Klerk, D. J. (1973), Geneeskunde 15:227.

Foerster, O. (1908), Zeitschr. Orthoped. Chir. 22:202223.

Foerster, O. (1913), Surg. Gynec. Obstet. 16:463-474.

Fraioli, B. and Guidetti, B. (1977): J. Neurosurg. $46: 618$

Gros, C., Ouaknine, G., Vlahovitch, B. (1967), Neurochirurgie 13:505.

Harris P. and Simpson, J. A. (1964): Int. J. Paraplegia $1: 197$.

Horsley, V. (1890), Brit. med. J. 2:1286.

Horsley, V. (1909), Brit. med. J. 2:125.

Kirk, E. G. and Denny-Brown, D. (1970), J. Comp. Neurol. 139:307.

Krynauw, R. A. (1950), J. Neurol. Neurosurg and Psychiat. 13:243.

Lacombe, M., Audie, B. and Maury, M. (1966-67), Paraplegia 4:164.

Maspes, P. E. and Pagni, C. A. (1964), J. Neurosurg. 21:1076.

McKissock, W. (1953), Proc. R. Soc. Med. 46:431.

Myers, R. (1942), Res. Publ. Ass. Res. Nerv. Ment. Dis. $21: 602$.

Munro, D. (1945), New Engl. J. Med. 233:453-461.

Munro, D. (1952), New Engl. J. Med. 246:161-166.

Narabayashi, H., and Okuma, T. (1953), Psych. Neurol. Jap. 54:672.

Narabayashi, H. and Kubota, K. (1966), Progr. Brain Res. 21B:339.

Nashold, B. S. and Slaughter, D. G. (1969): J. Neurosurg. $31: 172$.

Nathan, P. W. (1959), Lancet. 2:1099.

Nathan, P. W. (1965), Brit. med. J. 1:1096-1100.

Penfield, $W$. and Jasper, H. (1954), Epilepsy and the functional anatomy of the human brain. Churchill. London.

Putnam, T. (1942), Res. Publ. Ass. Res. Nerv. Ment. Dis. 21:666.

Dis. 21:666. (1969), Clin. Neurosurg. 16:288.
Rasmussen, T.

Sano, K. (1966), Progress in Brain Research. Amsterdam, Elsevier 21B:350.

Walker, A. E. (1949), Acta Psychiat. Neurol. 24:723.

Wilson, P. J. E. (1970), Brain 93:147. 